\title{
Effects of polyester fibers and gamma irradiation on mechanical properties of polymer concrete containing $\mathrm{CaCO}_{3}$ and silica sand
}

\author{
E. A. Bobadilla-Sánchez ${ }^{1}$, G. Martínez-Barrera ${ }^{1,2}$, W. Brostow ${ }^{2 *}$, T. Datashvili ${ }^{2}$ \\ ${ }^{1}$ Laboratorio de Investigación y Desarrollo de Materiales Avanzados (LIDMA), Facultad de Química, Universidad \\ Autónoma del Estado de México, Km. 12 de la carretera Toluca-Atlacomulco, San Cayetano 50200, Mexico \\ ${ }^{2}$ Laboratory of Advanced Polymers \& Optimized Materials (LAPOM), Department of Materials Science and Engineering \\ and Department of Physics, University of North Texas, 1150 Union Circle \# 305310, Denton TX 76203-5017, USA
}

Received 17 March 2009; accepted in revised form 3 July 2009

\begin{abstract}
While mineral concretes belong to the oldest composites used by mankind, in an increasing number of applications their compression strength $\sigma_{c}$ and compressive strain at yield point $\varepsilon_{Y}$ are insufficient. Better results can be achieved with polymer concretes (PCs). We use a polymer concrete (PC): an unsaturated polyester resin as the matrix, $\mathrm{CaCO}_{3}$ and silica sand. Moreover, we have applied two further methods to improve its mechanical properties: reinforcement with polyester fibers and gamma irradiation with a ${ }^{60} \mathrm{Co}$ source. A non-irradiated $\mathrm{PC}$ with $5 \mathrm{wt} \% \mathrm{CaCO}_{3}$ has $\sigma_{c}=74 \mathrm{MPa}$, an irradiated sample with optimized $\mathrm{CaCO}_{3}$ contents $122 \mathrm{MPa}$. Scanning electron micrographs show that irradiation increases the interface areas between the fibers and the matrix. Improvements from 47 to $176 \%$ in $\varepsilon_{Y}$ values are achieved with respect to the conventional PC without fibers, non-irradiated and containing only one mineral component.
\end{abstract}

Keywords: mechanical properties, polymer concrete, fiber reinforcement, gamma irradiation

\section{Introduction}

A large variety of concretes is based on a variety of cements [1-3]. Mineral concretes - used for a very long time - typically contain structural defects, including delaminations and voids. Polymer concretes (PCs) with a polymeric resin matrix have better mechanical properties than mineral concrete. Thus, PCs are used to make reinforced slabs, overlays for highway pavements and bridge decks, pipe coatings - as well as in repairing deteriorated mineral concretes (Portland cement concrete).

The key criteria for usability of a concrete for a specific application are compression strength $\sigma_{c}$ and compressive strain at yield point $\varepsilon_{Y}$. While PCs have these parameters better than mineral concretes, in potential applications still better values of $\sigma_{c}$ and
$\varepsilon_{Y}$ than those presently available are required. At least three options deserve consideration:

a) Use of fibers for reinforcement. There is a large variety of reinforcements for polymeric matrices [4-6]. The work of San-Jose et al. suggests using fibers or other objects with irregular shapes and large sizes since the adhesion between the reinforcement and the matrix depends on the physical interactions between them [7]. Similarly, elongated objects provide more improvement of mechanical properties that spherical ones [8]. This should not be surprising; Kopczynska and Ehrenstein [9] discuss how interfaces largely determine properties of multiphase materials.

b) Use of small particles as a dispersed phase. Special attention to the shape, size and number of 
aggregates is needed because the aggregates act as stress concentration points. Some PCs contain only one aggregate, others more than one, such as a PC with quartz fine sand, quartz gravel, quartz powder and chalk [7]. Moreover, the interface surface area can be enhanced by decreasing the size of the aggregate particles (inclusive to nano-dimensions), so as to produce strong cohesion; undesirable agglomeration of the particles has to be avoided. The Zagreb group has shown that $\mathrm{CaCO}_{3}$ with surface modification provides stronger bonding to polymers largely via electrostatic forces; moreover, $\mathrm{CaCO}_{3}$ without pre-treatment provides stronger interfacial adhesion than after a treatment [10]. An improvement of the attraction between the polymer and the aggregates can also be achieved by adding a coupling agent such as silane to the monomer. This lowers the extent of pore formation and causes a decrement in stiffness [11]. Our main interest consists in grafting polymers onto aggregates surfaces. c) Irradiation - by a variety of sources [12-19]. Gamma irradiation has several advantages over conventional curing processes: I) no catalyst or additives are needed to initiate the reaction; II) the initiation is homogenous throughout the system; III) it can be performed at any temperature and be interrupted at a chosen reaction time; IV) the polymer can be analyzed at selected reaction stages; and V) the temperature during reaction initialization is maintained - as contrasted with highly exothermic curing without irradiation. Moreover, the gamma irradiation applied to polymers causes three different processes: chain scission, crosslinking or grafting. Which of these processes prevails depends on the nature of irradiation, chemical nature of the polymer and the applied dose [20].

In this situation we have investigated a PC containing an unsaturated polyester resin, $\mathrm{CaCO}_{3}$ and silica sand - with inclusion of polyester fibers and gamma irradiation for their further reinforcement.

\section{Materials and procedures}

Our PC specimens consist of natural silica, calcium carbonate (GOSA ${ }^{\mathrm{TM}}$, Atizapan, Mexico), and a commercial unsaturated pre-accelerated orthophthalic polyester resin, a viscous liquid with $30 \%$ styrene monomer (Polylite 32493-00 ${ }^{\mathrm{TM}}$, Reichhold, Atlacomulco, Mexico). Methyl ethyl ketone peroxide is the initiator of free-radical polymerization
( $1 \mathrm{ml} / 100 \mathrm{~g}$ polyester). The sizes of silica sand particles were of 150, 212 and $355 \mu \mathrm{m}$ (mesh 100, 70 and 45 , respectively), and for $\mathrm{CaCO}_{3}$ particles $75 \mu \mathrm{m}$ (mesh 200). The standard mixing procedure according to the ASTM C305 was followed. It consists of two stages, mixing for 1.0 minutes at the paddle speed of $140 \mathrm{rpm}$, and followed by a total of 1.5 minutes at the speed of $285 \mathrm{rpm}$. The compositions of PCs are summarized in Table 1.

After mixing, $\mathrm{PC}$ cubic specimens with the side of $5.0 \mathrm{~cm}$ were kept at $23.0 \pm 3.0^{\circ} \mathrm{C}$ for 72 hours. Six different lots were elaborated (labeled I to VI) on different days, each one containing 15 samples. That is, for each type of PC (see Table 1) 15 concrete specimens were made.

For obtaining fiber-containing PCs, we have also followed the ASTM C305 mixing method, adding in the two stages the polyester fibers (Gütermann Polygal, Cuernavaca, Mexico) with diameters between 30 and $40 \mu \mathrm{m}$ and $20 \mathrm{~mm}$ long. The compositions of PCs with fibers are listed in Table 2. Three different lots were elaborated (labeled VII to IX) on different days, each one contained 15 samples. That is, for each polyester-fiber content 15 concrete specimens were made.

The PC specimens were subjected to gamma irradiation using a ${ }^{60} \mathrm{Co}$ source at five different dosages: $0,5,10,50$ and $100 \mathrm{kGy}$ at the rate of $2.48 \mathrm{kGy} / \mathrm{h}$ in air at room temperature. For comparison analysis, polyester fibers alone were irradiated under the same conditions, in packets of 50 fibers in a capillarity tube. The source was a 651 PT Gammabeam Irradiator, manufactured by Atomic Energy of Canada Ltd. (now NORDION, Chalk River,

Table 1. Compositions of the polymer concrete specimens

\begin{tabular}{|c|c|c|c|}
\hline $\begin{array}{c}\text { Specimen } \\
\text { (type) }\end{array}$ & $\begin{array}{c}\text { Polyester resin } \\
{[\mathbf{w t} \%]}\end{array}$ & $\begin{array}{c}\mathbf{C a C O}_{3} \\
{[\mathbf{w t} \%]}\end{array}$ & $\begin{array}{c}\text { Silica sand } \\
{[\mathbf{w t} \%]}\end{array}$ \\
\hline I & 20 & 5 & 75 \\
\hline II & 20 & 12 & 68 \\
\hline III & 20 & 25 & 55 \\
\hline IV & 20 & 37 & 43 \\
\hline V & 20 & 50 & 30 \\
\hline VI & 20 & 60 & 20 \\
\hline
\end{tabular}

Table 2. Compositions of the fiber + polymer concrete specimens

\begin{tabular}{|c|c|c|c|c|}
\hline Specimen & $\begin{array}{c}\text { Polyester } \\
\text { resin [wt\%] }\end{array}$ & $\begin{array}{c}\mathrm{CaCO}_{3} \\
{[\mathbf{w t} \%]}\end{array}$ & $\begin{array}{c}\text { Silica sand } \\
{[\mathbf{w t} \%]}\end{array}$ & $\begin{array}{c}\text { Polyester } \\
\text { fiber [wt\%] }\end{array}$ \\
\hline VII & 20.0 & 60.0 & 19.90 & 0.10 \\
\hline VIII & 20.0 & 60.0 & 19.75 & 0.25 \\
\hline IX & 20.0 & 60.0 & 19.60 & 0.40 \\
\hline
\end{tabular}


Ontario), and located at the Institute of Nuclear Sciences of the National Autonomous University of Mexico.

Compressive strength testing was performed in an Instron Universal Testing machine Model 1125, according to the ASTM C-109M standard. The charge speed used was of $120 \mathrm{~kg} / \mathrm{s}$, holding the charge until reaching the maximum value to assure the test reliability.

\section{Compression strength}

In Figure 1 we show the compressive strength values $\sigma_{c}$ for PCs without fibers. For non-irradiated PCs, $\sigma_{c}$ values increase according to the $\mathrm{CaCO}_{3}$ and silica sand concentrations; the lowest increment is seen for PC type I and the highest for PC type VI (see Table 1). That is, the compressive strength values increase when increasing $\mathrm{CaCO}_{3}$ and decreasing silica sand concentration at the same time. The compressive strength values vary from 74 to $107 \mathrm{MPa}$.

Similar behavior is seen in irradiated PCs, with the values varying from 85 to $122 \mathrm{MPa}$. The highest value of $122 \mathrm{MPa}$ is achieved for PC type V (50/30 $\mathrm{CaCO}_{3} /$ silica sand $\mathrm{wt} \%$ ratio), irradiated at $100 \mathrm{kGy}$. This result constitutes an improvement of $64 \%$ with respect to the minimum value obtained for nonirradiated PC type I.

The next step was evaluation of effects of polyester fibers incorporation into the PC. We have chosen those PCs in which variations in the compressive strength values were minimal. Thus, PC type VI was selected (see Figure 1) since the differences did not exceed $8 \%$.

The results for polyester-fiber PCs are shown in Figure 2. The $\sigma_{c}$ values in non-irradiated samples are lowered by introduction of the fibers. However

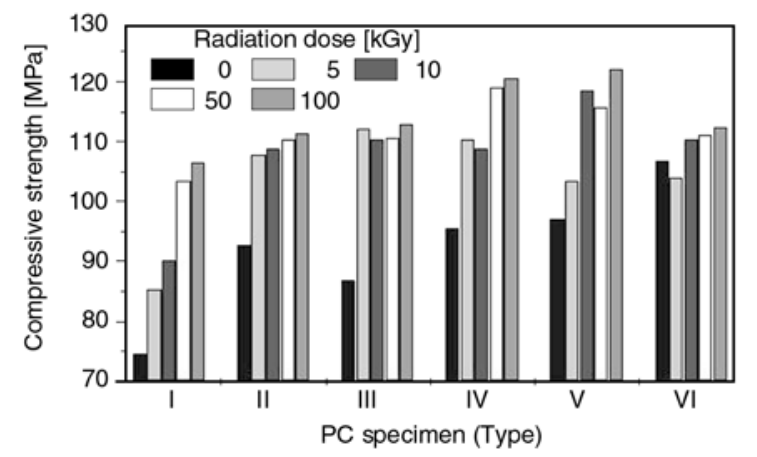

Figure 1. Compressive strength of different types of PCs

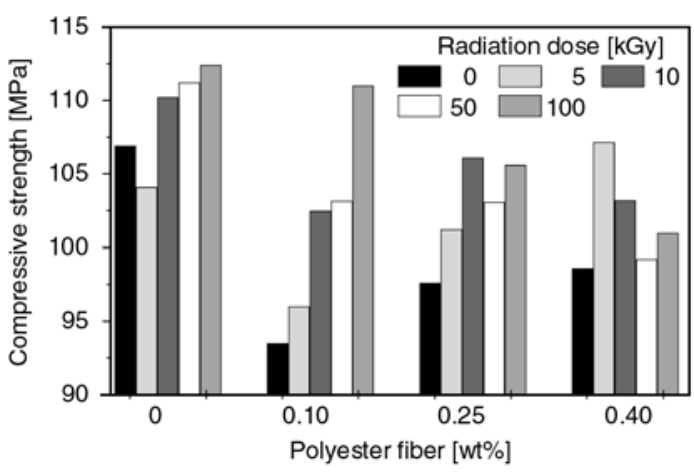

Figure 2. Compressive strength of fiber-reinforced PCs with varying polyester fiber concentrations

and as expected, $\sigma_{c}$ values depend on a combination of the fiber concentration and the applied radiation. By following the fiber concentrations, a different behavior is seen. For PCs with $0.1 \mathrm{wt} \%$ of fiber, the compressive strength values increase along with increasing applied radiation dose. For $0.25 \mathrm{wt} \%$, the compressive strength increases up to $10 \mathrm{kGy}$, then it decreases at $50 \mathrm{kGy}$, and finally it increases again at $100 \mathrm{kGy}$; for $0.4 \mathrm{wt} \%$, the highest value is seen at $5 \mathrm{kGy}$. In this sense, we can describe this $\sigma_{c}$ behavior as periodic. More notable is the periodicity if a fixed radiation dose is followed.

For fiber-PCs, the highest $\sigma_{c}$ value is seen for $0.1 \mathrm{wt} \%$ fibers and $100 \mathrm{kGy}$ of radiation dose. Recall that in Figure 1 the highest overall $\sigma_{c}$ value is also for $100 \mathrm{kGy}$. This can be related to effects of irradiation on polyester resins reported by Jurkin and Pucić [18]. At $5 \mathrm{kGy}$ the irradiated polyester resin abruptly changes from a viscous liquid into a hard thermoset solid (3-D network), reducing the polymer chains mobility [18] - what enhances $\sigma_{c}$. Between 5 and $50 \mathrm{kGy}$, the changes can be attributed to behavior of the fibers since the polyester resin retains its dimensional stability. For doses exceeding $50 \mathrm{kGy}$, the polyester resin begins to deteriorate [18] and lower $\sigma_{c}$ values are seen.

As said, the $\sigma_{c}$ values go from 74 to $107 \mathrm{MPa}$ for non-irradiated $\mathrm{PCs}$ when varying the $\mathrm{CaCO}_{3}$ and silica sand concentration; the respective range for irradiated PCs is $85-122 \mathrm{MPa}$. We recall in this context also earlier results for the same polyester resin containing whether $\mathrm{CaCO}_{3}$ or silica sand. The present results are lower than those reported for PCs containing only $\mathrm{CaCO}_{3}$ (from 127 to $135 \mathrm{MPa}$ ) [21], but higher than those obtained using silica sand only (from 62 to $68 \mathrm{MPa}$ ) [22]. Thus, in irradi- 


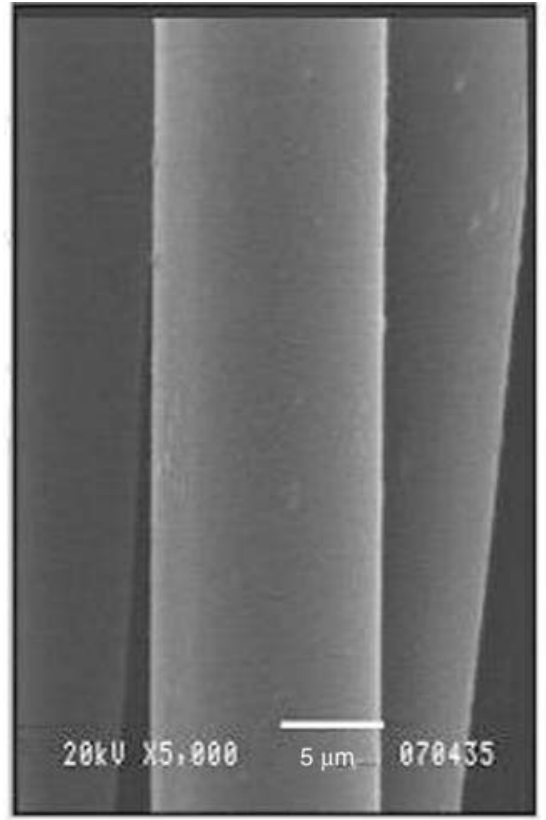

a)

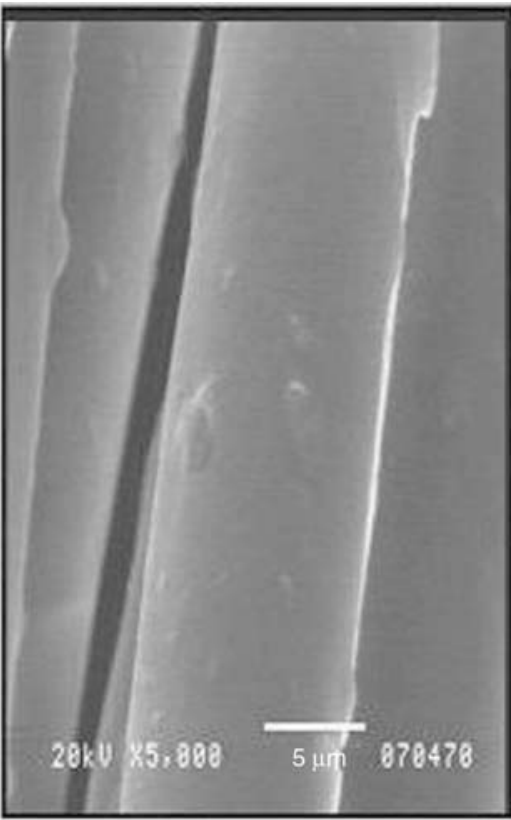

b)

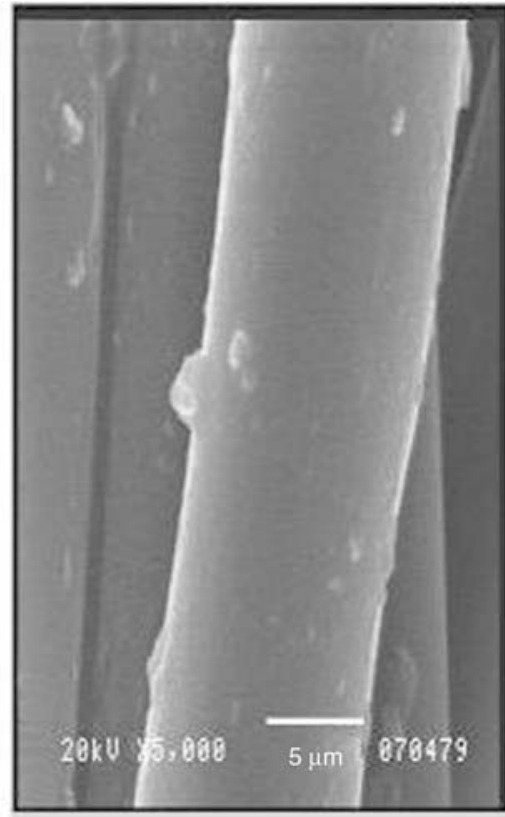

c)

Figure 3. SEM Micrographs of polyester fibers: non-irradiated (a), irradiated at $10 \mathrm{kGy}$ (b), and irradiated at $100 \mathrm{kGy}$ (c)

ated materials $\mathrm{CaCO}_{3}$ particles support more compression strength than the silica sand particles. Changes on surfaces of irradiated polyester fibers were observed by scanning electron microscopy (SEM). First the fibers were vacuum-coated with carbon (3-10 nm thickness) in a vacuum pump at 50 mTorr. A JEOL model JSM-5200 was used in the secondary electron mode. For non-irradiated fibers smooth and homogeneous surfaces are seen (Figure 3a). For 10 kGy several 'particles' are observed on the fiber surface (Figure 3b). At $100 \mathrm{kGy}$, SEM reveals more such particles (Figure 3c). Apparently irradiation causes a fractional degradation of the fiber surfaces - manifested as formation of the 'particles'.

Chain scission results in formation of low molecular weight chains at higher doses, providing more contact points and thus improving physical adhesion between the fibers and the concrete. As one of the consequences, the concrete will resist larger loads by inclined forces - oriented at some angles relative to the longitudinal axes of the fibers.

\section{Compressive strain at yield point}

We now turn to the compressive strain at yield point $\varepsilon_{Y}$ results. For non-irradiated PCs we see three well defined stages: increment-decrementincrement associated with $\mathrm{CaCO}_{3}$ and silica sand concentration (Figure 4). This periodic behavior

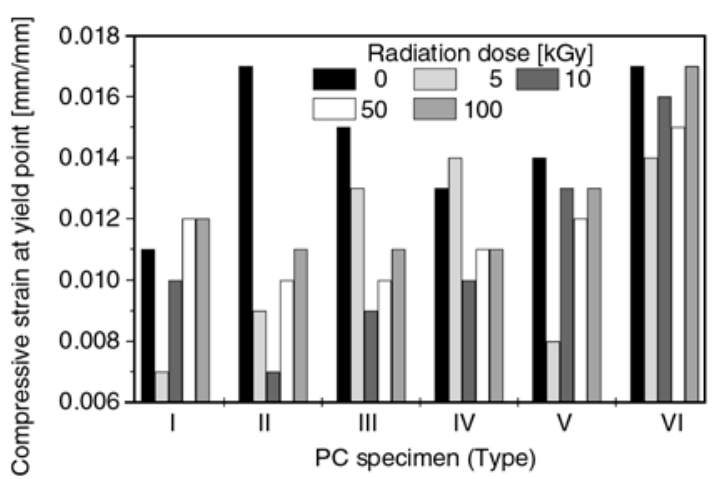

Figure 4. Compressive strain at yield point of different types of PCs

seems to be the result of a competition between two reinforcing components, $\mathrm{CaCO}_{3}$ and silica sand.

For irradiated PCs two different types of behavior are seen: I) three well-defined stages, with a increment-decrement-increment sequence - observed only in PCs irradiated at $5 \mathrm{kGy}$, II) two stages, with a decrement-increment sequence, observed in PCs irradiated at 10,50 and $100 \mathrm{kGy}$. The values for irradiated and non-irradiated PCs vary from 0.007 to $0.017 \mathrm{~mm} / \mathrm{mm}$. Apparently, the strain is supported by the polyester resin - a polymeric material - more than by mineral components $\mathrm{CaCO}_{3}$ and silica sand.

The highest values for PCs without fibers are seen for PC type VI (20/60/20 resin/ $\mathrm{CaCO}_{3} /$ silica ratio). Thus, this material was chosen as a convenient reference material for evaluation of effects of gamma 


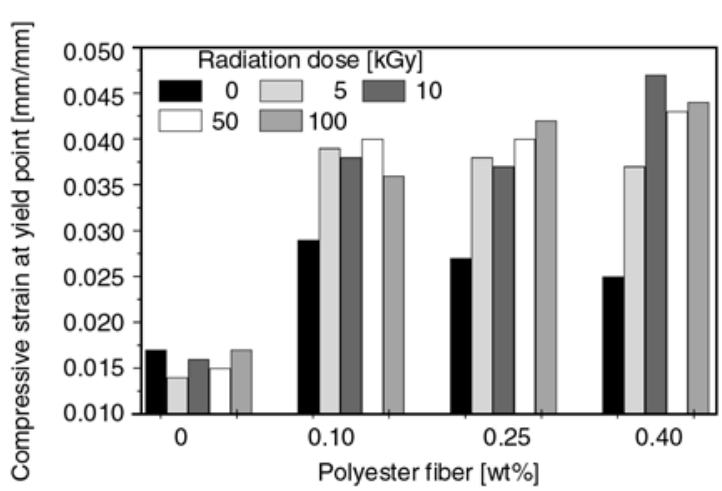

Figure 5. Compressive strain at yield point of fiber-reinforced PCs with varying polyester fiber concentrations

irradiation after addition of polyester fibers. The addition of the fibers, even only $0.1 \%$, increases $\varepsilon_{Y}$ tremendously, see Figure 5. The compressive strain values for fiber-PCs ranging from 0.025 to $0.047 \mathrm{~mm} / \mathrm{mm}$ are higher than standard values reported in the literature for polyester-based PC $(0.010 \mathrm{~mm} / \mathrm{mm})$ [20]. We note improvements from 47 to $176 \%$ with respect to conventional PCs (without fibers and non-irradiated).

We recall that the materials brittleness $B$ is inversely proportional to $\varepsilon_{Y}[23,24]$. If the dynamic storage modulus $E^{\prime}$ values ( $E^{\prime}$ also appears in the definition of $B$ ) are comparable, our materials with higher $\varepsilon_{Y}$ values are less brittle. Thus, irradiation of fibers causes material softening, and they sustain the compressive strain much more than the polyester resin.

Compare now our $\varepsilon_{Y}$ range of $0.025-0.047 \mathrm{~mm} / \mathrm{mm}$ with results for PCs with the same polyester resin but containing one mineral, such as $\mathrm{PC}$ with $\mathrm{CaCO}_{3}$ $(0.01-0.016 \mathrm{~mm} / \mathrm{mm}$ [21]) or with silica sand $(0.006-0.013 \mathrm{~mm} / \mathrm{mm}$ [22]); we conclude that a combination of two different minerals and one kind of polymeric fibers result in higher compressive strain values that in PCs containing one mineral.

\section{Compression modulus of elasticity}

In Figure 6 we show values of the compression modulus of elasticity $E_{c}$ for PCs without fibers. Also here periodic behavior is seen. For non-irradiated PCs the values range from 5.4 to $8.9 \mathrm{GPa}$, thus higher than our result for pure polyester resin, $E_{c}=$ 3.9 GPa [20]; as expected, adding the minerals increases $E_{c}$.

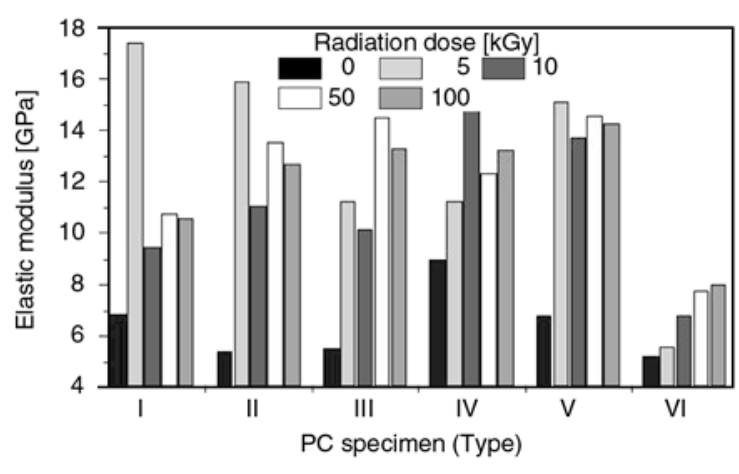

Figure 6. Compression modulus of elasticity $E_{c}$ of different types of PCs

Consider now $E_{c}$ values for irradiated PCs. There is a large variety of behavior, no general pattern; the $E_{c}$ ranging from 8.6 to $17.4 \mathrm{GPa}$ which are higher than values reported for polyester-based PCs (6.7 GPa) [22]. The highest value is for PC with 5\% of $\mathrm{CaCO}_{3}$ and $75 \%$ of silica sand irradiated at $5 \mathrm{kGy}$. This means an improvement of $159 \%$ respect to standard value reported in the literature [22].

The addition of polyester fibers lowers $E_{c}$ dramatically (results not included here for brevity). Both irradiated and non-irradiated PCs have results in the range from 3.1 to $3.7 \mathrm{GPa}$. Hence, the addition of the fibers increases ductility.

We have obtained notable improvements in the compressive strength and compressive strain at yield point - a consequence of contributions of irradiation, two aggregates $\left(\mathrm{CaCO}_{3}\right.$ and silica sand) as well as polyester fibers. Such behavior is not seen in polyester-based PCs with one aggregate.

\section{Acknowledgements}

Financial support by the National Council of Science and Technology of Mexico (CONACyT), Mexico City (Grant \# 49899/2005) and by Hispanic and Global Studies Initiatives Fund of the University of North Texas, Denton, are acknowledged.

\section{References}

[1] Mindess S.: Concrete materials. Journal of Materials Education, 5, 983-1046 (1983).

[2] Regourd M.: New progress in inorganic building materials. Journal of Materials Education, 9, 201-228 (1987).

[3] Roy D. M., Scheetz B. E., Silsbee M. R.: Processing of optimized cements and concretes via particle packing. Journal of Materials Education, 15, 1-16 (1993). 
[4] Rabello M.: Additives for Polymers. Artliber, São Paulo (2000).

[5] Pisanova E., Zhandarov S.: Fiber-reinforced heterogeneous composites. in 'Performance of plastics' (ed.: Brostow W.), Hanser, Munich, 461-486 (2000).

[6] Bismarck A., Mohanty A. K., Aranberri-Askargorta I., Czapla S., Misra M., Hinrichsen G., Springer J.: Surface characterization of natural fibers; Surface properties and the water up-take behavior of modified sisal and coir fibers. Green Chemistry, 3, 100-107 (2001). DOI: 10.1039/b100365h

[7] San-José J. T., Vegas I., Ferreira A.: Reinforced polymer concrete: Physical properties of the and static/ dynamic bond behaviour. Cement and Concrete Composites, 27, 934-944 (2005).

DOI: 10.1016/j.cemconcomp.2005.06.004

[8] Roslaniec Z., Broza G., Schulte K.: Nanocomposites based on multiblock polyester elastomers (PEE) and carbon nanotubes (CNT). Composite Interfaces, 10, 95-102 (2003).

DOI: $\underline{10.1163 / 156855403763586819}$

[9] Kopczynska A., Ehrenstein G. W.: Polymeric surfaces and their true surface tension in solids and melts. Journal of Materials Education, 29, 325-340 (2007).

[10] Leskovac M., Kovacevic V., Lucic Blagojevic S., Vsarljko D., Volovskek V.: Pre-treatment of $\mathrm{CaCO}_{3}$ nanofiller by irradiation in the presence of vinyl monomers. e-Polymers, no. 033 (2004).

[11] Brostow W.: Performance of plastics. Hanser, Munich (2000).

[12] Brocka Z., Schmachtenberg E., Ehrenstein G. W.: Radiation crosslinking engineering thermoplastics for tribological applications. in 'Proceedings of SPEANTEC 2007, Cincinnati USA' 1690-1694 (2007).

[13] Nair P. D., Sreenivasan K., Jayabalan M.: Multiple gamma radiation sterilization of polyester fibres. Biomaterials, 9, 335-338 (1988). DOI: $10.1016 / 0142-9612(88) 90029-4$

[14] Fink D.: Fundamentals of ion-irradiated polymers. Springer, Berlin (2004).

[15] Brostow W., Castano V. M., Horta J., Martinez-Barrera G.: Gamma irradiation effects on impact strength and thermal properties of SBR-toughened polystyrene. Polimery, 49, 9-14 (2004).
[16] Brostow W., Castaño V. M., Martinez-Barrera G.: Gamma irradiation effect on polystyrene+SRB blends: Morphology and hardness. Polimery, 50, 27-32 (2005).

[17] Martinez-Barrera G., Vigueras-Santiago E., Hernandez-Lopez S., Menchaca-Campos C., Brostow W.: Concrete reinforced with irradiated nylon fibers. Journal of Materials Research, 21, 484-491 (2006). DOI: $10.1557 / j m r .2006 .0058$

[18] Jurkin T., Pucić I.: Post-irradiation crosslinking of partially cured unsaturated polyester resin. Radiation Physics and Chemistry, 75, 1060-1068 (2006). DOI: 10.1016/j.radphyschem.2006.04.001

[19] Menchaca-Campos C., Martínez-Barrera G., Resendiz M. C., Lara V. H., Brostow W.: Long term irradiation effects on gamma-irradiated Nylon 6, 12 fibers. Journal of Materials Research, 23, 1276-1281 (2008). DOI: 10.1557/jmr.2008.0152

[20] Martínez-Barrera G., Brostow W.: Fiber-reinforced polymer concrete: Property improvement by gamma irradiation. in 'Gamma radiation effects on polymeric materials and its applications' (ed.: Barrera C.) Research Signpost, Kerala, 27-44 (2009).

[21] Martínez-Barrera G., Espinosa-Pesqueira M. E., Brostow W.: Concrete+polyester $+\mathrm{CaCO}_{3}$ : Mechanics and morphology after gamma irradiation. e- Polymers, no. 083 (2007).

[22] Martínez-Barrera G., Texcalpa-Villarruel U., Vigueras-Santiago E., Hernández-López S., Brostow W.: Compressive strength of gamma-irradiated polymer concrete. Polymer Composites, 29, 1210-1217 (2008). DOI: $10.1002 /$ pc. 20432

[23] Brostow W., Hagg Lobland H. E., Narkis M.: Sliding wear, viscoelasticity and brittleness of polymers. Journal of Materials Research, 21, 2422-2428 (2006). DOI: $10.1557 / j m r .2006 .0300$

[24] Brostow W., Hagg Lobland H. E.: Predicting wear from mechanical properties of thermoplastic polymers. Polymer Engineering and Science, 48, 1982 1985 (2008).

DOI: $\underline{10.1002 / \text { pen. } 21045}$ 